\title{
Mirakel inom \\ äldreomsorgen? - idén om en salutogen äldreomsorg och dess omsättning i praktiken
}

\section{MAIRON JOHANSSON \& ANN-SOFIE BERGMAN}

Begreppet salutogenes har under senare år blivit populärt inom äldreomsorgen. Trots detta har det saknats empiriska undersökningar om innebörden av salutogent perspektiv. Artikeln handlar om hur idén om ett salutogent synsätt och arbetssätt kommer till, översätts, sprids, för att omsättas $i$ praktik inom äldreomsorgen i en medelstor svensk kommun.

\section{Inledning och syfte}

I flera svenska kommuner pågår för närvarande arbetet med att införa ett salutogent synsätt och arbetssätt inom äldreomsorgen. Vikten av att äldre ska kunna uppleva en känsla av sammanhang och mening betonas. Synsättet får också stöd i nationell äldrepolitik (SOU 2008:51; SOU 2008:126; prop. 2009/10:116). Ett tydligt exempel är ett tillägg i socialtjänstlagen som anger att omsorgen ska leda till värdigt liv och välbefinnande för

Mairon Johansson \& Ann-Sofie Bergman, lektorer institutionen för socialt arbete, Linnéuniversitet de äldre, vilket bygger på uppfattningen att vardagen ska vara begriplig, hanterbar och meningsfull (SFS 2010:427; jfr prop. 2009/10:116, s. 9). Uttrycken salutogen och meningsfullhet tas även upp i Socialstyrelsens (2012) "vägledningsmaterial" för personal om värdegrund. Det kan dock nämnas att diskussioner om meningsfull tillvaro för äldre även har förts i tidigare lagstiftningsarbeten, det är således inte en helt ny fråga (se prop. 1996/97:124, s. $120 \mathrm{ff}$.)

Hur begreppet salutogen förstås och används kan variera och ges lite skiftande betydelser på olika nivåer och av olika aktörer. Fokus i denna artikel är den 
kommunala nivån. En kommun som har anammat den salutogena idén inom äldreomsorgen beskriver på sin hemsida att den största skillnaden jämfört med tidigare arbetssätt är att "personalen kommer att ha en mer coachande roll". I en annan kommun uppfattas det salutogena handla om att sätta individen i centrum och utgå från "det goda". Några argument som lyfts fram för det salutogena syn- och arbetssättet är att "alla vinner på detta" och att det också handlar om att "hushålla med resurser". ' Idén om en salutogen äldreomsorg är aktuell just nu men det finns mycket få studier om det salutogena perspektivets betydelse och konsekvenser i praktiken. Gassne (2008) pekar på en kunskapslucka om vad salutogent perspektiv i socialt arbete innebär.

Syftet med denna artikel är att belysa och analysera hur idén om ett salutogent synsätt och arbetssätt kommer till och hur idén översätts, sprids och omsätts i praktik inom äldreomsorgen i en medelstor svensk kommun.

\section{Antonovskys teori om salutogenes}

Aaron Antonovsky, professor i medicinsk sociologi, har utvecklat teorin om salutogenes som i korthet innebär fokus

1 http://goteborg.se/wps/portal/enheter/ ovrigaenheter/senior-goteborg, 2012-12-10; http://www.katrineholm.se/Halsa-stod-ochomsorg-/Aldreomsorg/Projektutvecklingsarbeten/Stimulansmedel/Salutogent-synsatt/2012-12-10 på hälsofrämjande faktorer. Även om Antonovsky var sociolog påverkades han av psykologiska teorier. Antonovskys första publikation om salutogenes gavs ut år 1979 och finns senare även presenterad i en bok från 1987 (svensk översättning år 1991). I samband med en undersökning av hur israeliska kvinnor anpassat sig till klimakteriet, började Antonovsky intressera sig för varför vissa människor behåller sin hälsa trots svåra påfrestningar. Resultatet av studien visade att en grupp kvinnor som hade överlevt vistelse i koncentrationsläger, trots svåra livserfarenheter ändå bedömdes ha tillfredsställande psykisk och fysisk hälsa. Medan man utifrån ett patogent synsätt förklarar vad som gör människor sjuka, innebär det salutogena att förklara vilka omständigheter som bidrar till god hälsa trots att människor utsätts för avsevärda sjukdomsframkallande stressorer. Antonovsky menade att hälsa och ohälsa inte ska ses som en dikotomi utan som ett kontinuum och betonade att det patogena och det salutogena synsättet är komplementära, det ena ska inte ersätta det andra. Han såg det dock som ett problem att ensidigt fokusera på det patogena som tidigare varit dominerande, hans förhoppning var en bättre balans mellan de båda synsätten (Antonovsky 1991).

Antonovsky intresserade sig för vad han kallade generella motståndsresurser - exempelvis pengar, jagstyrka och socialt stöd - som ger kraft att bekämpa de olika stressorer som människor ständigt utsätts för. Genom upprepade erfarenheter av begripliggörande skapas en känsla av sammanhang (kasam) enligt Antonov- 
sky. I kasam inbegrips tre centrala komponenter: Begriplighet handlar om i vilken utsträckning människan upplever inre och yttre stimuli som förnuftsmässigt gripbara, som information som är sammanhängande, strukturerad och tydlig. Hanterbarhet avser upplevelsen av att resurser står till ens förfogande med hjälp av vilka man kan möta de krav som ställs. Det kan handla om resurser som är under ens egen kontroll men även resurser som kontrolleras av andra. Meningsfullhet är kasambegreppets motivationskomponent och rör i vilken utsträckning man känner att livet har en känslomässig innebörd, att problem och krav är värda att investera energi $i$, värda engagemang och hängivelse (Antonovsky 1991, s. 39 f.). Vidare menade Antonovsky att de tre komponenterna är sammanflätade. Framgångsrik problemhantering är beroende av kasam $\mathrm{i}$ sin helhet. Han diskuterade att meningsfullhet förefaller vara den viktigaste komponenten och begriplighet troligtvis den näst viktigaste eftersom hanterbarhet förutsätter förståelse, men betonade dock att hanterbarhet inte är oviktigt. Vid låg hanterbarhet, det vill säga om man inte tror att man har tillgång till resurser, avtar upplevelsen av meningsfullhet och strävan att hantera situationen avtar (Antonovsky 1991, s. 44 f.). För att kunna mäta människors kasam utvecklade Antonovsky ett kasamformulär/enkät.

Antonovsky lyfte själv fram kritik mot den salutogena teorin. Han såg en fara med det holistiska synsättet där i stort sett allt $i$ en persons liv har betydelse och menade att risken är att synsättet inom organisationer kan bli "en oändlig expansion av social kontroll i händerna på dem som dominerar detta system" (Antonovsky 1991, s. 32). Tishelman (1998) och Theorell (1998) tar upp kritiska synpunkter som risken att bortse från sammanhanget och makronivån när kasam används som ett psykologiskt mått och att det kan bli ytterligare ett sätt att skilja mellan normala och onormala, starka och svaga människor. En okritisk användning av kasam kan därmed innebära att personal i en verksamhet sorteras och stämplas som olämpliga på felaktiga grunder. Tishelman (1998) diskuterar även risken att teorin används i tider av neddragningar inom den offentliga sektorn. Används den endast för salutogena ändamål? Kommer den att gynna de svaga eller finns det risk att begreppet och dess komponenter missbrukas?

\section{Tidigare forskning om kasam och salutogenes}

Antonovskys begrepp salutogenes och kasam har studerats internationellt och i Sverige. Sökningar i olika databaser (sökord salutogenesis och sense of coherence) visar att begreppen har använts inom olika ämnesområden. Ett par tidiga exempel är empiriska studier där det kasamformulär/ enkät Antonovsky utvecklade har prövats, dels inom forskning om funktionsnedsättning, dels inom barn och familj (Antonovsky \& Sourani 1988; Chamberlain \& Zika 1988). Det har vidare varit en stadig ökning av studier om känsla av sammanhang på båda dessa områden. Från och med 1990-talet används begreppen inom 
nya forskningsområden som rör folkhälsa, hälso- och sjukvård, psykiatri, psykoterapi, flyktingmottagning, äldre/äldreomsorg, utbildning. Senare tillkomna områden är ledarskap, arbetsmiljö (exempelvis Feldt, Kinnunen \& Mauno 2000; Albertsen, Nielsen \& Borg 2001) och olika professioners upplevelse av kasam (Björkman \& Carlsson 2007; Gassne 2008) som blev aktuella först på 2000-talet. Begreppen har inte varit lika vanliga inom äldreomsorg som inom folkhälsa som har varit det vanligaste området över tid. Dock har den största ökningen skett inom just äldreomsorg.

Inom äldreomsorgsforskningen har det framför allt handlat om kvantitativa studier där Antonovskys kasamformulär/ enkät prövats i olika sammanhang. Flertalet studier har genomförts i Sverige, Tyskland, USA, men även i exempelvis Norge, Israel, Australien, Polen. Svenska studier har företrädesvis fokus på äldre inom hälso- och sjukvård och psykiatri (exempelvis Johansson, Larsson \& Hamrin 1998; Mellqvist m.fl. 2011). Rennemarks (1999) avhandling i psykologi belyser dock äldres upplevelse av hälsa utifrån kön och de sociala nätverkens betydelse. I en relativt nygjord publikation av Eriksson \& Häger (2012) dokumenteras ett aktions-forskningsprojekt vid en FoU-enhet. Projektets syfte var att utveckla kvaliteten inom omsorg och vård för äldre utifrån ett salutogent perspektiv, i den meningen att vård och omsorg ska bygga på och uppmärksamma de äldres resurser. Till skillnad från tidigare svenska studier där Antonovskys kasamformulär/enkät använts genomförs intervjuer med vård- och omsorgspersonal i det senast nämnda aktionsforsk- nings-projektet. Eriksson \& Hägers (2012) dokumentation verkar dock vara den enda svenska studien där salutogent perspektiv inom äldreomsorgen bygger på empiriskt material utifrån äldreomsorgspersonalens perspektiv. En slutsats är således att tidigare svensk forskning som berör äldre och/eller äldreomsorg är knapphändig och främst handlar om användning av Antonovskys kasamformulär/enkät.

\section{Översättningsteori}

Som framgått är studiens syfte att belysa och analysera hur idén om ett salutogent synsätt och arbetssätt kommer till och hur idén översätts, sprids och omsätts i praktik inom äldreomsorgen. Analysen genomförs med utgångspunkt från en specifik riktning inom nyinstitutionell teori. Idéers spridning kan studeras utifrån ett diffusionsteoretiskt eller ett översättningsteoretiskt perspektiv vilka dock inte är väsensskilda. Båda perspektiven fokuserar hur idéer sprids och synliggör oftast de aktörer som tar till sig nya idéer. Emellertid finns en skillnad som har betydelse för hur idéspridning studeras. Enkelt uttryckt fokuserar diffusionsperspektivet hur idéer överförs från ett sammanhang till ett annat medan översättningsperspektivet tar fasta på hur en ursprunglig idé översätts, det vill säga hur den tolkas i samband med att idén hämtas och förs in i annat sammanhang eller annan kontext (Johansson 2011). Diffusionsperspektivet har en lång forskningstradition och används inom olika discipliner. Diffusionsforskaren Rogers (2003) beskriver idéprid- 
ning genom diffusion som en process där informationen om nya idéer kommuniceras. Det skiljer sig från Czarniawska \& Joerges (1996) utvecklade översättningsteori där fokus är att förstå hur nya idéer tolkas av aktörer för att dessa idéer ska passa in i en ny kontext. Studier som belyser nya idéers spridning och tolkning inom svensk äldreomsorg är få. Blomberg (2004) har dock undersökt hur en marknadsorienterad organisationsmodell (specialiserad bistånds-handläggning) översatts och spridits till äldreomsorg. I uppföljande studie av Blomberg \& Petersson (2011) undersöks vidare vad som hänt med den marknadsorienterade modellen några år efter dess införande. Ytterligare studier rör andra verksamhetsområden inom vård och socialtjänst (jfr Blom 1998; Erlingsdottír 1999; Grape 2001; Markström 2003; Ineland 2006; Hollertz 2010; Ponnert \& Svensson 2011) och ideella organisationer engagerade inom välfärdens kärnområden (Linde 2010; Johansson 2011).

Denna studie analyseras utifrån översättningsteori och med stöd av några centrala begrepp såsom frikoppling, förpackning och omsättning $i$ handling. Czarniawska \& Joerges (1996) utgångspunkt är att olika idéer cirklar runt omkring i världen och får fotfäste på olika platser. För att idéer ska kunna resa behöver någon/ några intressera sig för en ursprunglig idé, genom att exempelvis läsa om den eller träffa andra aktörer som berättar om idén. På så sätt gör människor sina "verkligheter" tillgängliga för varandra. Begreppet frikoppling innebär att den ursprungliga idén blir kontextlös, eller med Furustens ord (2007, s. 80) den de-kontextualiseras, rums- och tidsbundna drag skalas bort. Det gör idén objektiv och samtidigt tolkningsbar. När idén bäddas in på en ny plats hamnar den i en annan kontext. Den nya kontexten och idébärarnas tolkning gör att den ursprungliga idén kan förändras. Människor som för över idéer gör något med dem, de knyter samman den ursprungliga idén med egna idéer för att den ska passa in i ett nytt sammanhang på en ny plats. Vid översättningen av nya idéer omvandlas således originalet helt eller delvis till något annat. Människor som tar emot och sprider nya idéer är därmed inte bara transportörer utan även transformatörer. För att kunna få fotfäste och tas emot av flera aktörer förpackas idéer, exempelvis som texter, modeller eller bilder. Czarniawska \& Joerges (1996) liknar förpackade idéer vid paket som skickas iväg till nya platser och nya människor. Konferenser, marknadsföring och publikationer är framgångsrika sätt för att sprida idéer (a.a.). Massmedia kan också vara betydelsefulla spridningsarenor (Johansson 2002). Slutligen möter idén den lokala praktiken där den ska omsättas $i$ handling av dem som fått i uppgift att förverkliga idén, en process Furusten (2007) kallar för idéns re-kontextualisering.

\section{Metod och material}

Studien bygger på analyser av en utvald kommuns äldreomsorgspraktik. Materialet består av omsorgsförvaltningens egenproducerade texter; fokusgruppsintervjuer med fyra grupper vård- och omsorgspersonal (åtta till tolv personer per grupp) 
inom hemtjänst och särskilt boende; individuella intervjuer med fem enhetschefer och fyra personer i förvaltningsledningen. Intervjuerna genomfördes under perioden hösten 2011 till och med sommaren 2012 i samband med utvärderingen av ett projekt med fokus på kompetensutveckling av personalen. I utvärderingen genomfördes även en enkätstudie bland personalen, vilken kan ses som ett bakgrundsmaterial även om den inte explicit används i denna artikel. Återkommande ledord under kompetensutvecklingen var salutogenes och kasam. Förvaltningsledningen ville införa ett salutogent syn- och arbetssätt inom omsorgsförvaltningen. På det lokala planet har vi särskilt intresserat oss för vård- och omsorgspersonalens perspektiv - de som i verksamheten befinner sig allra närmast de äldre. Vi har analyserat deras uppfattning om vad det innebär att arbeta salutogent och deras upplevelse av förutsättningarna för syn- och arbetssättet. Intervju- och textmaterialet har vidare analyserats med hjälp av analysverktygen problem-orsak-lösning (Bergström \& Boréus 2005). Med utgångspunkt från detta analysverktyg kan införandet av ett salutogent syn- och arbetssätt ses som en lösning på ett problem inom äldreomsorgen. Vi har med hjälp av dessa verktyg sökt i materialet efter; vilka är de angivna problem som ska lösas, vad anges som orsaker till problemen och hur presenteras lösningen.

Ytterligare ett material i studien är forskaren Peter Westlunds publikationer om det salutogena perspektivet. När vi har arbetat med analyser av varifrån ledningen i den aktuella kommunen hämtat idén om en salutogen äldreomsorg har det visat sig att Westlund varit en central aktör i idéspridningen. Hans tolkning av Antonovskys salutogena perspektiv har haft stort inflytande för förvaltningsledningens uppfattningar. Även Westlunds publikationer om salutogenes, utgivna åren 2002-2012, har analyserats med hjälp av analysverktygen problem-orsak-lösning (Bergström \& Boréus 2005). ${ }^{2}$

\section{Tolkning med koppling till en svensk äldreomsorgskontext}

Idén om salutogent perspektiv kommer ursprungligen från Antonovsky. Forskaren Westlund har bidragit till tolkningen och spridningen av idén inom svensk äldreomsorg genom en rad böcker. ${ }^{3}$ Dessutom sprids tolkningen via artiklar i Tidningen Äldreomsorg. ${ }^{4}$ I förordet till ett par böcker anges att boktitlarna ingår i ett "salutogent bibliotek" eftersom det salutogena synsättet ses som lösning på framtidens äldreomsorg (Westlund 2010, s. 5; Westlund \& Duckert 2012, s. 5). Innehållsmässigt handlar böckerna om ämnen som: salutogent arbetssätt

2 Efter 2012 har författaren publicerat ytterligare en bok inom temat salutogen äldreomsorg (salutogen hemtjänst och hemsjukvård) som dock inte ingår i analysen.

3 Av de nio böcker vi funnit har Westlund skrivit några själv medan andra har en eller flera medförfattare.

4 Exempelvis 2004:5, s. 36-44; 2006:4, s. 31; 2006:6, s. 33-37; 2011:2, s. 14-16; 2013:2, s. 32-35; 2014:2, s. 18-21. 
(Westlund 2002; Westlund \& Sjöberg 2005; Westlund \& Sjöberg 2008; Westlund 2012); salutogen ekonomi (Westlund \& Lindberg 2012); salutogen rehabilitering (Westlund 2009a); salutogent bemötande (Westlund 2009b); salutogen design av äldreboenden (Westlund 2010) och salutogen biståndshandläggning (Westlund \& Duckert 2012). Gemensamt för dessa böcker är att de inte bygger på systematiska empiriska studier som rör de äldres eller personalens upplevelser och erfarenheter. Författarna hänvisar till exempel från andra studier och till egna "professionella kunskaper och erfarenheter men också av de erfarenheter vi gör i vardagslivet som familjefäder, makar, söner och i vänskapsrelationer" (Westlund \& Sjöberg 2005, s. 10). I litteraturen argumenterar författarna för hur äldreomsorgen bör utformas för att vara salutogen, det vill säga bidra till de äldres känsla av sammanhang.

Följande avsnitt handlar om Westlunds argument för ett salutogent syn- och arbetssätt inom äldreomsorgen. ${ }^{5}$ Vilka problem i dagens äldreomsorg förväntas det salutogena lösa? Vad framställs som orsak till problemen och vad innebär lösningen? (jfr Bergström \& Boréus 2005).

Analysen visar att de problem som framställs handlar om: i) det patogena perspektivet har för stort genomslag inom äldreomsorgen; ii) dagens äldreomsorg har för stort fokus på hanterbar-

5 I följande avsnitt refererar vi till enbart Westlund även om det finns medförfattare till flera av titlarna, då vi uppfattar honom som huvudförfattare och huvudsaklig uttolkare av det salutogena syn- och arbetssättet. het på bekostnad av meningsfullhet och begriplighet; iii) det finns en felaktig föreställning om att äldreomsorgen lider brist på ekonomiska resurser.

Vad gäller de orsaker till ovan nämnda problem, som framställs i litteraturen, visar analysen att dessa uppfattas handla om: i) personalens syn- och arbetssätt utgår för mycket från rutiner och deras egna arbetsrelaterade intressen; ii) personal och anhöriga undervärderar de äldres egna förmågor; iii) de äldres egna resurser tas inte till vara tillräckligt; iv) befintliga ekonomiska och personella resurser används fel. Orsaker som personalens problematiska syn- och arbetssätt samt föreställningar om bristande resurser uttrycks bland annat på följande sätt:

Flertalet [av dem som arbetar inom äldreomsorgen] sitter fast $i$ ett tänkande som hämmar verklig utveckling. Vi itutas gång efter annan att huvudproblemen är bristen på resurser och medicinsk kompetens (Westlund \& Sjöberg 2008, s. 6).

Angående lösningar på ovanstående problem föreslås en övergripande lösning som innebär att äldreomsorgen bör ställas om till salutogent synsätt och arbetssätt. Med salutogent synsätt avses att: i) verksamheten genomsyras av en kultur som prioriterar de äldres meningsfullhet och begriplighet framför hanterbarhet; ii) personalen har gemensam grundsyn," rätt värderingar är viktigare än rätt kompetens"(Westlund 2012, s. 76).

Med salutogent arbetssätt avses att: i) mer insatser bör ges i hemmet snarare än att erbjuda särskilt boende; ii) bistånds- 
beslut bör inte fattas på sjukhus utan i den äldres hem några dagar efter hemkomst, eftersom den patogena sjukhuskulturen präglas av att sjukvårdspersonal och även anhöriga styr och menar att äldre har större vård- och omsorgsbehov än de i själva verket har; iii) utgå från individens behov i stället för "institutionella rutiner och handlingsmönster" (Westlund 2009a, s. 7); iv) arbeta utifrån ett funktionsstödjande arbetssätt, ge "hjälp till självhjälp" (jfr Westlund 2010, s. 18); v) uppmuntra de äldre till en aktiv livsstil.

För att iscensätta ett salutogent arbetssätt behövs även strukturella förutsättningar för personalen såsom exempelvis hjälpmedel, kompetens, tillräcklig bemanning och en stödjande ledning (Westlund \& Sjöberg 2005; Westlund \& Sjöberg 2008; Westlund 2009a).

\section{Tre aspekter på Westlunds tolkning av Antonovsky}

Westlund argumenterar för salutogenes inom äldreomsorgen. Med utgångspunkt från resultat av studien på kommunnivå vill vi lyfta fram tre aspekter i hans tolkning: Den första aspekten handlar om förhållandet mellan det patogena och det salutogena synsättet. Enligt Antonovsky ska inte det salutogena synsättet ersätta det patogena utan de ska vara kompletterande perspektiv. Han såg det som ett problem att bara fokusera på det patogena och föreslog en bättre balans mellan synsätten (Antonovsky 1991). Som vi uppfattar Westlund tonas komplementariteten ned varmed han ser stora risker med ett patogent synsätt: "Som vi bedömer det är det synnerligen riskfyllt att låta det patogena synsättet och den sjukdomsorienterade praktiken svara för vården och omsorgen av kroniskt sjuka äldre" (Westlund \& Sjöberg 2005, s. 45). Vår reflektion är således att det patogena synsättet tonas ner då "komplementariteten har en gräns" (Westlund \& Sjöberg 2005, s. 45) vilket innebär att det salutogena perspektivet är väldigt centralt och därmed bör ges företräde. Westlund menar att äldreomsorgen behöver ställas om/förändras radikalt (Westlund \& Sjöberg 2008, s. 9). Samtidigt som komplementariteten diskuteras menar vi att perspektiven ställs emot varandra. Man ska dock beakta att det skett förändringar av den offentliga äldreomsorgens omfattning. Studier visar att andelen äldre som får hjälp har minskat under tre decennier då resurserna under samma tid har minskat (Szebehely \& Trydegård 2007; Szebehely \& Ulmanen 2012), samtidigt har de allra äldstas hälsa blivit sämre (Thorslund m.fl. 2004). I en intervju i Läkartidningen 2007 säger äldreforskaren Mats Thorslund att gapet mellan de äldres behov och tillgången till resurser har ökat sedan $1980 .{ }^{6}$

Den andra aspekten handlar om personalens möjligheter att stärka kasam hos de äldre i den grad att det kan leda till mirakel:

$V i$ menar att när omsorgen och vården ställs om, när de drivs och planeras i salutogen anda, så uppstår förändringar som är nära nog oförklarliga, närmast miraku-

6 Läkartidningen 2007:24f. 
lösa. Sådana mirakel kan handla om äldre som på ett närmast obegripligt sätt återfår förmågor och resurser (Westlund \& Sjöberg 2008, s. 10).

I vilken utsträckning kan personalen stärka äldres kasam på detta radikala sätt? Antonovsky (1991) menade att kasam formas under människors olika livsfaser, främst tidigt i livet. Han såg kasam som ett stabilt och varaktigt hållningssätt vilket påverkas av faktorer som erfarenheter under uppväxten, kultur, social struktur, historisk kontext samt känsliga skeenden under livet. En viktig poäng hos Antonovsky är att kasam formas både av individen själv och av dennes omgivning, det vill säga psyko-sociala faktorer. Antonovsky menade vidare att kasam tillfälligt kan förändras i någon riktning men att det snart faller tillbaka till personens "normala" nivå igen. Enligt Gassne reviderade Antonovsky denna uppfattning om kasams stabilitet. Senare forskning om begreppet har visat att skillnader i kasam över tid kan hänga samman med faktorer som förankring på arbetsmarknaden, inkomst, yrkesstatus och hälsofaktorer, vad gäller hälsoaspekter särskilt för äldre personer (se Gassne 2008, s. 46; Lundberg 1998; Bergsten 1998).

Till skillnad från Antonovsky som menade att kasam formas av både individen själv och av omgivningen uppfattar vi att Westlunds tolkning är att äldres kasam formas av den närmaste omgivningen. Medan Antonovsky fokuserade psyko-sociala faktorer fokuserar Westlund på de sociala och diskuterar inte att de äldres kasam formats av psykologiska faktorer och livshändelser. Tilltron till att omgivningen, i detta fall personalen, kan stärka de äldres kasam är stor. Tolkningen innebär en väsentlig förskjutning av begreppet.

Den tredje aspekten rör argumentet att hanterbarheten bör nedprioriteras till förmån för meningsfullhet och begriplighet (Westlund \& Sjöberg 2008, s. 24; Westlund 2009a, s. 28; Westlund 2010, s. 85). Tolkningen av Antonovskys kasambegrepp är att meningsfullhet och begriplighet bör ha högsta prioritet medan hanterbarhet bör ges lägst prioritet. Problemet anses vara att praktisk hanterbarhet har fått för hög prioritet $i$ dagens vård och omsorg och att de äldre på så vis fråntas möjlighet att använda egna resurser och att upptäcka sina egna förmågor. Detta kallas "hanterbarhetens paradox" då det kan motverka sina egna syften enligt Westlund \& Sjöberg (2008, s. 87). Antonovsky å sin sida menade att framgångsrik problemhantering är beroende av kasam $\mathrm{i}$ dess helhet. Hanterbarhet nedprioriteras av Westlund på ett sätt som vi inte uppfattar hos Antonovsky (Antonovsky 1991, s. 44 f.; Antonovsky 1987, s. 22).

Dessa tre ovan nämnda aspekter är exempel på hur Westlund tolkar Antonovsky. Den nya kontexten, det vill säga kopplingen till äldreomsorgen och idébärarnas tolkning, gör att den ursprungliga idén har förändrats. Som Czarniawska \& Joerges (1996) anger gör människor som för över idéer något med dem, de knyter samman den ursprungliga idén med egna idéer för att den ska passa in i ett nytt sammanhang på en ny plats. Vid översättningen av idéer omvandlas således origi- 
nalet helt eller delvis till något annat. I kommande avsnitt visar vi ett exempel på hur denna översättning landar i en lokal kommunal kontext.

\section{Spridning till en lokal kontext}

Westlund är med Czarniawska \& Joerges (1996) ord en central transformatör som sprider idén om salutogent syn- och arbetssätt inom äldreomsorgen till den kommunala nivån. Enligt egen utsaga är Westlund en flitigt anlitad utbildningsledare och föreläsare i många kommuner (Westlund \& Sjöberg 2008, s. 9). För att kunna spridas och få fotfäste anger Czarniawska \& Joerges (1996) att idéer behöver förpackas. Författarna (a.a.) liknar förpackade idéer vid paket som skickas iväg till olika platser och nya människor. Konferenser, marknadsföring och publikationer är framgångsrika sätt för att sprida idéer (a.a.). I denna undersökning framkommer att idén förpackas genom Westlunds och hans medarbetares böcker, men presenteras främst muntligt i och med Westlunds personliga deltagande i en rad olika utbildningsaktiviteter i kommunen. Idén sprids på en rad olika arenor. Den första spridningsarenan var en storföreläsning om "En resa i salutogen vägledning". Här deltog i stort sett samtliga av de omkring 600 personer som arbetar inom kommunens vård- och omsorgsverksamheter (äldreomsorg, handikappomsorg, hemsjukvård, missbruksvård och psykiatri). Andra spridningsarenor utgjordes av särskilda utbildningssatsningar till enhetschefer i "salutogent ledarskap", kollegie-gransk- ning med fokus på ett" salutogent tänk och arbetssätt", en utbildning som benämndes som "auskultation" eller med personalens ord "salutogen granskning". Andra exempel är arenor där ärendeutredare och biståndshandläggare fick utbildning i "salutogen handläggning". Benämningarna på de olika utbildningssatsningarna visar att inspiration hämtats från Westlunds terminologi.

\section{Tolkning i den lokala kontexten}

Vad innebär det salutogena enligt förvaltningsledningen? Ledningen menar att det finns behov av en genomgripande förändring av syn- och arbetssätt i organisationen. De talar om att målet är att man i verksamheten ska gå från ett personalperspektiv till ett verksamhetsperspektiv och sätta fokus på sitt uppdrag. Personalen måste tydligare förstå varför de går till jobbet, att det handlar om att stödja andra människor i deras livssituation, att gå från ett omhändertagandeperspektiv till ett stödjande perspektiv. Ett problem som lyfts fram är att personalen lätt hamnar i schema- och personalfokusdiskussioner istället för att ägna tid åt de äldre. Andra problem som ledningen lyfter fram är att personalen benämner sig själva som vårdare och att man arbetar inom vården, vilket anses vara knutet till ett patogent syn- och arbetssätt. En person inom ledningen säger att personalen inom äldreomsorgen i själva verket utför "socialt arbete till säkert 90 procent" och menar att den interna "kulturen" behöver för- 
ändras. Inom ledningen finns vidare uppfattningen att dessa problem kan lösas genom att enhetscheferna "tar till sig" det salutogena syn- och arbetssättet så att de i sin tur kan vara ett stöd för personalen. Någon betonar att arbetet inom äldreomsorgen kräver en teoretisk grund och uttrycker att det salutogena "är gångbart i allt när man pratar om att få människor att växa”. Enhetscheferna anses ha en nyckelposition i att införa arbetssättet och att vara salutogena chefer i förhållande till sin personal. Det salutogena innebär vidare, enligt ledningen, att titta på den enskilde äldres resurser och möjligheter i stället för att leta efter problem. Sammantaget illustrerar detta att ledningen, i linje med Westlunds tolkning av Antonovsky, tar fasta på att personalen och kulturen är oerhört centrala för utvecklingen av en salutogen äldreomsorg. Till skillnad från Westlund som i viss mån tar upp strukturella förutsättningar, så som exempelvis tillräcklig bemanning (Westlund \& Sjöberg 2005) för att personalen ska kunna arbeta salutogent, fokuserar inte ledningen på dessa aspekter. Här sker således en ny tolkning i den lokala kontexten (jfr Czarniawska \& Joerges 1996). Strukturella förutsättningar ses inte som hinder, utan det är personalens problematiska syn- och arbetssätt som behöver förändras. Analysen visar att förvaltningsledningen anpassar sig och tar tag i det som man uppfattar som mindre besvärligt att förändra utifrån rådande ekonomiska förutsättningar. "Vi har vår budget" säger en person i ledningen, och menar att man inte har för avsikt att försöka påverka denna.

\section{Idén omsätts i handling}

I följande avsnitt diskuteras vad som sker i den lokala kontexten när ledningens idé om ett salutogent syn- och arbetssätt inom äldreomsorgen omsätts i praktisk handling. Enhetscheferna anges av förvaltningsledningen ha en nyckelposition i att införa och förankra det salutogena i praktiken. Hur tolkar då enhetscheferna begreppen salutogenes och kasam? Analysen visar att de talar om vikten av att "likrikta tänket" inom förvaltningen och kan sammanfattas med orden att ha fokus på det friska, att äldreomsorgen karaktäriseras av äldres delaktighet och vikten av aktivitet som leder till upplevelser av meningsfullhet. En enhetschef menar att det här ligger i linje med hur man redan arbetar, att "det går i linje med att arbeta med helheten". Enhetscheferna ser vidare inte att bemanningen är det stora hindret för att arbeta salutogent utan lyfter främst fram användningen av resurser: "Bemanningen är begränsad". Av det skälet måste man titta på hur man arbetar och använda de äldres egna resurser: "Det hjälper inte alltid med mer personal utan vi måste titta på hur vi arbetar". De äldre ska vara mer delaktiga, säger en enhetschef:

Om de [omsorgstagarna] inte fär vara delaktiga, vad blir det för mening då? Ju mer de fär vara delaktiga, ju mer klarar de av. Det är jobbigt för personalen för det kan ta tidibörjan.

Citatet är ett exempel på en stor tilltro till att personalen genom sitt arbetssätt kan förbättra de äldres förmåga och upp- 
levelse av meningsfullhet, vilket också ligger i linje med Westlunds tolkning av salutogenes.

Det finns viss likhet mellan enhetschefernas och personalens tolkningar av vad salutogent perspektiv innebär. Liksom enhetscheferna beskriver personalen att salutogent syn- och arbetssätt handlar om att bevara det friska och att äldre bör vara aktiva för att uppleva meningsfullhet. Det kan röra sig om allt från möjligheten att exempelvis delta i gymnastik och bokcirklar till att vara aktiv i omsorgssituationer, exempelvis att få knäppa sina egna knappar under påklädning. Personalen som arbetar i det direkta mötet med äldre tar närmare upp en aspekt av salutogent synoch arbetssätt och som rör själva bemötandet av de äldre. Det handlar om respekt, lyhördhet, närvaro och att behandla äldre som man själv vill bli behandlad. Det är en form av etiskt förhållningssätt, en gyllene regel som innebär "att tänka med hjärtat". Personalen ger därmed uttryck för det som Eliasson-Lappalainen (1996) och Eliasson-Lappalainen \& Szebehely (1998) menar inbegrips i begreppet omsorg, att få praktisk hjälp (att ta hand om), av en känslomässigt engagerad person (att bry sig) och att få arbetet utfört med omtanke - det Eliasson-Lappalainen (1996, s. 9 f.) menar är en "hjärtesak".

Att personalens förståelse av vad ett salutogent syn- och arbetssätt innebär ligger så nära begreppet omsorg, kan förklaras av att de, till skillnad från förvaltningsledningen, inte anser att den utbildning de fått om salutogenes direkt har tillfört något nytt. Att bevara det friska och bidra till ett meningsfullt liv är något de eftersträvar, men menar kan vara svårt att genomföra. Ett exempel är den "guldkant" personalen på ett boende velat ge de äldre då varje individ ska få välja något de vill göra två gånger om året. Enligt personalen har de dock bara mäktat med att genomföra detta en gång per år.

\section{Dilemman i praktiken}

Samtidigt som personalen känner igen det salutogena lyfter de fram att det finns problem med perspektivet. I likhet med senare tids forskning (Thorslund m.fl. 2004; Szebehely \& Trydegård 2007; Szebehely \& Ulmanen 2012) bekräftar personalen att många äldre är väldigt sjuka när de väl får hjälp av äldreomsorgen på ett boende eller av hemtjänsten. Det innebär att möjligheterna att tillämpa ett salutogent arbetssätt är begränsade. När de äldre har så stora vård- och omsorgsbehov är det svårt att satsa på det friska, menar personalen:

Det har blivit svårare att få plats inom kommunen. Många blir äldre och dementa. De som är på demensboende är väldigt dåliga när de kommer. Det är svårt att bevara något, de är så dåliga när de kommer in /.../ det är inte så enkelt. Viljan finns oftast inte. De vill inte längre.

Ibland är de också väldigt dåliga [äldre som får hjälp av hemtjänsten], de väntar på att få en plats på boende. Vi kan vara hos vissa 8-10 gånger per dygn. Några får man åka ut och leta efter för att de har gått iväg. Då är det inte så lätt att tänka på kasam - att bevara det friska. 
Ett dilemma som personalen lyfter fram är att de inte ges tillräckliga förutsättningar för omsorgsarbetet. Det behövs mer personal. Periodvis är det en pressad arbetssituation då många äldre har omfattande vårdbehov. Att få "ett huvud extra" [en extra personal] kan vara avgörande för att man ska hinna med på arbetsplatsen. Ett problem är att ledningen ibland väljer att "nolla" [att dra ner på ordinarie bemanning] vid helger eller vid personals sjukdom och semester. En personal säger:

Jag kan bara ta ett exempel. Det var en midsommar, jag jobbade. Då var det nollat. Det är helgdag och det skulle dras ner på bemanningen. Vi skulle sitta och ha det lite mysigt och sitta med midsommarstämning. Men det var bara det att de pensionärer som skulle åka härifrån [för att fira midsommar med anhöriga] åkte ju inte innan, utan det kom mitt $i$ midsommarfirandet. Så då ska jag sitta och äta pedagogiskt med pensionärerna som är kvar, plus att det kom en dam utifrån som ska hämta en kvinna. De [omsorgstagarna] fick ta sin mailtid vid midsommarafton själva. Det hade jag inte styr på. Jag kan inte både vara vid måltiden och sköta det här utbytet. Förstår ni? Det tycker jag är skadligt. Så långt ner på bemanningen fär man inte gå så att det inte fungerar /.../ Man jobbar som ett svin och ska skapa helgstämning och det är omöjligt. Det går inte.

Ett annat dilemma som omsorgspersonalen pekar på är att de som är väldigt sjuka tar mycket tid, vilket får som följd att de äldre som är lite piggare får stå tillbaka. Då kan omsorgen snarare kännas "som förvaring bara". De begränsade förutsättningarna innebär att man känner sig stressad och otillräcklig. Medan förvaltningsledningen talar om att personalen inom äldreomsorgen främst bedriver socialt arbete, ger personalen uttryck för en annan vardagsverklighet. De beskriver att de möter människor med omfattande vård- och omsorgsbehov vilket innebär att de upplever ett behov av att tillgodogöra sig mer kunskap om sjukdomar och vård, det de möter i sin vardag. Det personalen ger uttryck för kan tolkas som att det patogena perspektivet också behövs bredvid det salutogena och inte bör tolkas bort, då de båda perspektiven ska ses som komplementära (jfr Antonovsky 1991).

\section{Avslutande diskussion}

Vad händer när idén om salutogenes översätts och sprids för att omsättas i en lokal praktik i svensk kommunal äldreomsorg? Den ursprungliga idén om salutogenes kommer från sociologen Antonovsky som i en studie fann att en del människor med traumatiska livserfarenheter (vistelse i koncentrationsläger) ändå kunnat behålla sin hälsa. Det salutogena perspektivet innebär fokus på hälsofrämjande faktorer. Forskaren Westlund transformerar idén till äldreomsorgen. Några i detta sammanhang avgörande aspekter i Westlunds tolkning av Antonovskys begrepp är att han betonar det salutogena perspektivet på bekostnad av det patogena, och att komponenten meningsfullhet accentueras medan hanterbarhet tonas ned. Vidare förflyttas fokus från människors 
egna upplevelser av god hälsa trots svåra livserfarenheter till ett personal- och verksamhetsperspektiv. Äldres livshändelser får litet utrymme medan tilltron till omsorgspersonalens möjligheter att stärka deras känsla av sammanhang är stor. Westlund visar dock inte att det kan fungera i praktiken då slutsatserna inte bygger på empiriska studier utan snarare utgörs av oprövade hypoteser.

Vi menar liksom Theorell (1998) att det är intressant att ta reda på vad som gör att människor har hög känsla av sammanhang. Huruvida och i vilken grad personal kan stärka omsorgstagarnas kasam är en empirisk fråga. Enligt Westlund är det framför allt kulturen inom äldreomsorgen som behöver ändras, resurser finns men används inte rätt. Denna tolkning sprids till omsorgsförvaltningens ledning. Av förvaltningsledningen görs en ny tolkning som kan sägas ligga nära Westlunds. Det är kulturen som behöver ändras. Förvaltningsledningens tolkning avviker dock från Westlunds i det avseendet att personalens hanterbarhet tonas ned. Ett exempel är att tillgången till resurser i form av tillräcklig bemanning inte blir en fråga, vilket den ändå i viss mån är hos Westlund (Westlund \& Sjöberg 2005).

När idén ska omsättas i praktik visar det sig att äldreomsorgspersonalen står för ett mer kritiskt perspektiv. De uppfattar inte att den salutogena idén direkt till- för ett nytt perspektiv, utan menar i stort att det är vad de redan eftersträvar i sitt arbete (jfr Eriksson \& Häger 2012). Enligt denna tolkning kan salutogen äldreomsorg inbegripas i det mer traditionella begreppet omsorg. Personalen belyser att många omsorgstagare är väldigt sjuka vilket innebär att det patogena perspektivet behöver få utrymme och komplettera det salutogena (jfr Antonovsky 1991). Omsorgspersonalen betonar vidare vikten av tillräckliga förutsättningar för att kunna utföra sitt arbete. Bemanningen upplevs som ett problem. En hanterbar arbetssituation är väsentlig för möjligheten att ge den omsorg och stimulans de äldre behöver (jfr Eriksson \& Häger 2012; Trydegård 2012). En rimlig belastningsbalans och adekvata resurser är avgörande för omsorgspersonalens känsla av hanterbarhet (jfr Antonovsky 1991). Om tillgången till personalresurser brister, kan det vara svårt att åstadkomma mirakel (jfr Westlund \& Sjöberg, 2008 s. 10).

De olika tolkningar som görs av aktörer på olika nivåer illustrerar hur idéer cirklar runt och omvandlas (Czarniawska \& Jorges 1996). De aktörer som dock saknas i den här framställningen är de äldre som får insatser inom äldreomsorgen. Vad som kan stärka deras känsla av sammanhang är en empirisk fråga, en studie som belyser äldres egna uppfattningar vore därmed intressant. 


\section{Referenser}

Albertsen, Kai, Michael L. Nielsen \& Vilhelm Borg (2001). The Danish psychosocial work environment and symptoms of stress: The main, mediating and moderating role of sense of coherence, Work \& Stress, Vol. 15, nr 3.

Antonovsky, Aaron (1987). Unraveling the Mystery of Health: How People Manage Stress and Stay Well. San Francisco, Calif.: Jossey-Bass.

Antonovsky, Aaron (1991). Hälsans mysterium. Stockholm: Natur och Kultur.

Antonovsky, Aaron \& Talma Sourani (1988). Family sense of coherence and family adaptation, Journal of Marriage and The Family, vol 50, nr 1,79-92.

Bergsten, Birgitta (1998). Känsla av sammanhang (kasam) utifrån en kvalitativ studie av unga barnfamiljer. I Thomas Kumlin (red.) Känsla av sammanhang i teori, empiri och kritik. Stockholm: Forskningsrådsnämnden.

Bergström, Göran \& Kristina Boréus (2005). Textens mening och makt: Metodbok $i$ samhällsvetenskaplig text- och diskursanalys. Lund: Studentlitteratur.

Björkman, Maja \& Ingegerd Carlsson (2007). Känsla av sammanhang på arbetet. Vilka faktorer på arbetsplatsen och hos individen främjar arbetsterapeuters upplevelse av ett meningsfullt arbete? Stockholm: Arbetslivsinstitutet.

Blom, Björn (1998). Marknadsorientering av socialtjänstens individ- och familjeomsorg. Om villkor, processer och konsekvenser. Diss. Umeå: Umeå Universitet, Institutionen för socialt arbete.

Blomberg, Staffan (2004). Specialiserad biståndshandläggning inom den kommunala äldreomsorgen. Genomförande av en organisationsreform och dess praktik. Diss. Lund: Lunds Universitet, Socialhögskolan.

Blomberg, Staffan \& Jan Petersson (2011). När en ny organisationsmodell blir vardag - spridningen av specialiserad biståndshandläggning inom den kommunala äldreomsorgen och vad som hände sen, Socionomens forskningssupplement, $\mathrm{nr} 29$.

Chamberlain, Kerry \& Sheryl Zika (1988). Measuring meaning in life: An examination of three scales, Personality and Individual Differences, vol. 9, nr 3, 589-596.

Czarniawska, Barbara \& Bernward Joerges (1996). Travels of Ideas. I Barbara Czarniawska \& Guje Sevón (red.) Translation Organizational Change. Berlin:Walter de Gruyter.

Eliasson-Lappalainen, Rosmari (red.) (1996). Omsorgens skiftningar: begreppet, vardagen, politiken, forskningen. Lund: Studentlitteratur.

Eliasson-Lappalainen, Rosmari \& Marta Szebehely (1998). Omsorgskvalitet i svensk hemtjänst - hotad eller säkrad av att mätas? I Rosmari Eliasson-Lappalainen \& Marta Szebehely (red.) Vad förgår och vad består?: En antologi om äldreomsorg, kvinnosyn och socialpolitik. Lund:Arkiv.

Eriksson, Bengt G. \& Birgit Häger (2012). Saluto gen omsorg och vård i praktiken: Omsorg och vård för ett helt liv. Karlstad: Karlstads universitet, FoUVälfärd.

Erlingsdottír, Gunbjörg (1999). Förförande idéer - kvalitetssäkring i hälso- och sjukvården. Diss. Lund:Lunds Universitet, Ekonomihögskolan.

Feldt, Taru, Ulla Kinnunen \& Saija Mauno (2000). A meditational model of sense of coherence in the work context: a one-year fellow-up study, Journal of Organizational Behaviour, vol. 21, nr 4,461-476.

Furusten, Staffan (2007). Den institutionella omvärlden. Malmö: Liber.

Gassne, Jan (2008). Salutogenes, Kasam och socionomer. Diss. Lund: Lunds universitet, Socialhögskolan.

Grape, Owe (2001). Mellan morot och piska. En fallstudie av 1992 års Rehabiliteringsreform. Diss. Umeå: Umeå Universitet, Sociologiska institutionen.

Mairon Johansson \& Ann-Sofie Bergman: Mirakel inom äldreomsorgen? 
Honnertz, Katarina (2010). Problemen förgår men lösningarna består. Organiseringen av kommunala insatser för unga arbetslösa med försörjningsproblem. Diss. Lund: Lunds Universitet, Socialhögskolan.

Ineland, Jens (2006). Konst, funktionshinder och frågan om legitimitet - om nya domänanspråk inom handikappfältet. I Owe Grape, Björn Blom \& Roine Johansson (red.) Organisation och omvärld - nyinstitutionell analys av människobehandlande organisationer. Lund: Studentlitteratur.

Johansson, Inger, Gerry Larsson \& Elisabeth Hamrin (1998). Sense of coherence, quality of life, and function among elderly hip fracture patients, Aging: Clinical And Experimental Research, vol. 10, nr 5,377-384.

Johansson, Mairon (2011). I dialogens namn-idén om en överenskommelse mellan regeringen och ideella organisationer. Diss. Växjö: Linnéuniversitetet, Institutionen för socialt arbete.

Johansson, Roine (2002). Nyinstitutionalismen inom organisationsanalysen - en skolbildnings uppkomst, spridning och utveckling. Lund: Studentlitteratur.

Linde, Stig (2010). Församlingen i granskningssamhället. Diss. Lund: Lunds Universitet, Socialhögskolan.

Lundberg, Olle (1998). "Känsla av sammanhang" ur ett befolkningsperspektiv. I Thomas Kumlin (red.) Känsla av sammanhang $i$ teori, empiri och kritik. Stockholm: Forskningsrådsnämnden.

Markström, Urban (2003). Den svenska psykiatrireformen - bland brukare, eldsjälar och byräkrater. Diss. Umeå: Boréa.

Mellqvist, Madeleine, Stefan Wiktorsson, Erik Joas, Svante Östling, Ingemar Skog \& Margda Wearn (2011). Sense of coherence in elderly suicide attempters: the impact of social and health-related factors. International psychogeriatrics, vol. 23, nr 6, 986-993.

Ponnert, Lina \& Kerstin Svensson (2011). När förpackade idéer möter organisatoriska villkor, Socialvetenskaplig Tidskrift, nr 3.

Proposition 1996/97:124, Ändring i socialtjänstlagen.

Proposition 2009/10:116, Värdigt liv i äldreomsorgen.

Rennemark, Mikael (1999). Wellbeing in old age: life history evaluations, sense of coherence and social networks in relation to health. Diss. Lund: Lunds universitet.

Rogers, Everett (2003). Diffusion of Innovations. New York: Free Press.

SFS 2010:427, Lag om ändring $i$ socialtjänstlagen 2001:453.

Socialstyrelsen (2012). Äldreomsorgens nationella värdegrund - ett vägledningsmaterial.

SOU 2008:51, Värdigt liv i äldreomsorgen. Betänkande av Värdighetsutredningen.

SOU 2008:126, I den äldres tjänst: Äldreassistent - ett framtidsyrke. Betänkande av Utredningen Yrkeskrav i äldreomsorg.

Szebehely, Marta \& Gun-Britt Trydegård (2007). Omsorgstjänster för äldre och funktionshindrade: Skilda villkor, skilda trender? Socialvetenskaplig Tidskrift, nr 2-3.

Szebehely, Marta \& Petra Ulmanen (2012). Åtstramningens pris: Hur påverkas de medelålders barnen av äldreomsorgens minskning? Stockholm: Stockholms universitet, Institutionen för socialt arbete.

Theorell, Töres (1998). "Antonovsky och hans kasam", Röster om kasam: 15 forskare granskar begreppet känsla av sammanhang. Stockholm: Forskningsrådsnämnden.

Thorslund, Mats, Carin Lennartsson, Marti G. Parker \& Olle Lundberg (2004). De allra äldstas hälsa har blivit sämre: Könsskillnaderna är stora - kvinnorna mår sämre än männen visar nya data, Läkartidningen, vol. 101, nr 17, 14941499.

Tishelman, Carol (1998). Några kritiska reflektioner över vårt okritiska bruk av KASAM. I Thomas Kumlin (red.) Känsla av sammanhang i teori, empiri och kritik. Stockholm: Forskningsrådsnämnden.

Trydegård, Gun-Britt (2012). Care work in changing welfare states: Nordic care workers' experiences, European Journal of Ageing, vol. 9, nr 
2,119-129.

Westlund, Peter (2002). Socialt synsätt $i$ äldreomsorgen: Emmaboda serviceområde. Kalmar: Fokus.

Westlund, Peter (2009a). Från rutin till behov: Salutogen rehabilitering. Kalmar: Fokus.

Westlund, Peter (2009b). Salutogen GPS - för ett gott bemötande. Solna: Fortbildning/Tidningen Äldreomsorg.

Westlund, Peter (2010). Salutogen design: är framtidens boende. Solna: Fortbildning/Tidningen Äldreomsorg.

Westlund, Peter (2012) (red.) Socialtjänst utan retur - ett medborgarperspektiv växer fram. Stockholm: Fortbildning AB/Tidningen Äldreomsorg.
Westlund, Peter \& Arne Sjöberg (2005). Antonovsky inte Maslow - för en salutogen omsorg och vård. Stockholm: Fortbildning/Tidningen Äldreomsorg.

Westlund, Peter \& Arne Sjöberg (2008). Planera för mirakel: Arbeta salutogent, stärk kasam. Stockholm: Fortbildning/Tidningen Äldreomsorg.

Westlund, Peter \& Malin Duckert (2012). Salutogen handläggning: bistånd enligt SoL inom äldreomsorgen. Solna: Fortbildning/Tidningen Äldreomsorg.

Westlund, Peter \& Gunnar Lindberg (2012). Salutogen ekonomi. Stockholm: Fortbildning/Tidningen Äldreomsorg. 


\section{Summary}

\section{Miracle in elderly care?-The idea of salutogenic elderly care and its implementation in practice}

This article is about how the idea of a salutogenic outlook and method comes into being, is translated and disseminated in order to be put into practice in elderly care. Although the idea of salutogenic elderly care has become popular in recent years, there has been a dearth of empirical studies of the meaning of this perspective. The original idea came from Antonovsky, who was interested in why some people retain their health despite severe strains. The material for the study consists of texts produced by a municipal department of elderly care, focus group interviews and individual interviews with staff and management, and text analyses of theories of salutogenesis. The analysis was conducted on the basis of a specific orientation in neo-institutional theory, the translation perspective, which examines how an original idea is interpreted when it is borrowed for use in a different context. The result shows that Antonovsky's original idea is transformed for the local context by Westlund. Crucial aspects of the new interpretation are the emphasis on the salutogenic perspective at the expense of the pathogenic; accentuation of the component of meaningfulness while manageability is toned down; trust in the potential of care staff to strengthen the elderly people's sense of coherence. Like Westlund, the management of the department of elderly care believe that a radical change is necessary in outlook and working methods. The internal culture needs to be changed. Unlike Westlund, who to some extent considers the structural conditions necessary if the staff are to be able to work salutogenically, the management does not focus on that. The interpretations made by actors at different levels illustrate how ideas circulate and are transformed. When translated into practice, the study shows that the care staff recognize the salutogenic way of thinking as being in line with the way they already wish to work. At the same time, they highlight problems. Dilemmas arise in that many elderly people are very ill when they finally get help, while those who feel somewhat fitter have to wait. The staff draw attention to inadequate personnel resources and difficulties with their manageability, which makes it hard to achieve the miracle described by Westlund. 